\title{
Collaborative Curriculum Design for Remote School District Service Learning
}

\author{
Chia-Ling Hsu
}

\begin{abstract}
This study is aim to develop and implement a service learning curriculum to a remote disadvantaged school district secondary school for pre-service teachers to practice their learning in teacher education course, "the curriculum design and development". The pre-service teachers applied the collaborative learning to design and develop one weak integrated curriculum for remote school district secondary school. 23 pre-service teachers and 36 students were in this project. The integrated curriculum was developed by pre-service teachers. Then the curriculum was implemented to those students who were low achievement in that secondary school. During the implementation, the pre-service teacher wrote their reflection and the self-efficacy test were held before and after.
\end{abstract}

Index Terms-Collaborative learning, curriculum and instruction, teacher education, service learning.

\section{INTRODUCTION}

From the point of Friedman's (2005) view that technologies, economics, and politics were affected each country, company, community and individual [1]. Therefore, many projects are ongoing in education, such as, "Every child matters at the heart of the curriculum" in England, "No child left behind" in the United States and "After school alternative program" in Taiwan [2]-[5]. These projects focus on disadvantage students learning.

The pre-service teacher program is in higher education for educating college students to be the secondary education teachers. Since the trend in higher education of service learning courses, the teacher program also recruits students practicing their teaching skills to service those children who are in remote educational district.

The purpose of this study is to provide a practical teaching setting for pre-service teachers to practice what they have learned in class. Since, the service learning courses or activities are the main indicator for building up the students' characters of globalization and care for the disadvantaged groups in higher education. Students, who attend the service learning courses or activities, usually will participate in different events with different people. Through the experience of activities, students build up their character of caring people as well as extend their vision of globalization. As a result, this study provided a practical teaching for pre-service teachers as well as to expand their abilities of teaching.

Manuscript received May 4, 2014; revised July 7, 2014

Chia-ling Hsu is with Tamkang University, New Taipei City, 25137, Taiwan (R.O.C.) (e-mail: clhsu@mail.tku.edu.tw).
The research hypothesis are:

- There is a significant difference in class management between the pre-test and the post-test in self-efficacy.

- There is a significant difference in teacher qualification between the pre-test and the post-test in self-efficacy.

- There is a significant difference in teaching strategies between the pre-test and the post-test in self-efficacy.

- There is a significant difference in the educational theories application between the pre-test and the post-test in self-efficacy.

The significance of this study is helping pre-service teachers enhance their teaching skill and self-efficacy. At the same time, through the collaborative learning, this study helped them to build up their cooperative skill. The vision of globalization was also stimulated when they developed the integrated service learning activities.

\section{RELATED LiterATURE}

\section{A. Service Learning}

Dr. Dewey emphasized that experiential learning will occur through the learning process in which students tend to create something of their own and make contributions to ultimate learning[6]-[8]. Dr. Lewin followed Dewey's theory and added an action research methodology to make the experiential learning to be an integration of theory and practice [9], [10]. Then, Dr. Piaget and Dr. Bruner turned a movement in curriculum and instruction for experience-based designs into college level courses [11], [12].

The service learning focuses on providing service as well as learning form the service activities [13]. However, Eyler (2000) indicated that the impact of service learning on college students needed to identify intellectual outcomes to embed into instructional design [14]. In order to assessing the outcome of service learning, Karayan and Gathercoal (2005) used a "ProfPort Webfolio System" for student service learning as teaching, learning, assessment and research tool [15]. The system somehow is part of traditional portfolio. So, how to improve the quality of service learning is back to how to investigate the reflection to making improving.

\section{B. Collaborative Learning}

The broadest definition of "collaborative learning" is that people attempt to learn something together said by Dillenbourg (1999) [16]. Nelson (1983) summarized some guidelines for collaborated learning. The categories are Instructor-Implemented Methods, Learner Implemented methods, Instructor and learner implemented methods and interactive methods [17]. The role of collaborative learning is 
more than a mere facilitator of events; it is the means by which such growth occurs and a provision for it must be amade in schooling [18].

\section{Instructional Design}

In the domain of curriculum and instruction are emphasizes not only designing an effective curriculum or instruction but also evaluation the students learning outcomes. No matter what approach the research used would lead to a reflection of instruction [19]-[23]. Marsh and Willis (1999) indicated that different school implemented the curriculum and instruction differently but it only a few models in total, the objective model, Countenance model, illuminative model and educational connoisseurship model [24].

Instructional design has two meanings. One is to provide teaching blueprints, and the other is to examine teaching and provide solutions. Accordingly, the practice of instructional design is to target specific learners, select specific approaches, contents, and strategies, and make an effective teaching policy [25] Given that effective teaching requires proper prior planning, there are several hypotheses about instructional design (Gagne, Briggs \& Wager 1992): 1). Teaching is aimed at promoting individual learning. 2). Instructional design is divided into immediate design and long-term design. Systematic instructional design has a great impact on individual development. 4). Instructional design should be produced systematically. 5). Instructional design involves the presentation and acquisition of knowledge on the basis of the learning theory and cognitive theory [26]. Hence, teaching materials should not be the presentation of what teachers know only. How to present teaching materials in order to facilitate learning must be taken into consideration as well.

Instructional design is often presented and explained through models. Currently, there are a variety of instructional design models, among which the ADDIE model is the most common one (Michael, Marlon \& Roberto 2002) [27]. The ADDIE model includes five phases: analyze, design, develop, implement, and evaluate. Due to its simplicity and viability, the ADDIE model is heavily used in instructional design of e-learning (Hsu \& Kuo 2000) [28]. The present study also used the ADDIE model to divide the process of the design and implementation of the web-based course into the above-mentioned five phases.

\section{RESEARCH METHOD}

This study was for the pre-service teachers to practice their learning by develop and implement the integrated service learning curriculum to the remote advantaged school district secondary low achievement students.

\section{A. Participants}

The study was conducted with pre-service teachers and secondary high school students who were participated in "Educational disadvantaged remote district teaching service learning activities". Twenty three pre-service teachers and twenty students were enrolled. 8 were male and fifteen were female in the pre-service teachers group. Twelve of them were no teaching experience at all. Although eleven pre-service teachers having some tutoring experience, they all had not the experience in a real class. These pre-service teachers' majors were variety, Math, English, Chinese, Japanese, and Business. The purposes of their attending were practicing their learning from teacher education program and increasing their teaching experiences. Table I show the distribution of the participants of the pre-service teacher.

TABLE I: THE DISTRIBUTION OF PARTICIPANTS

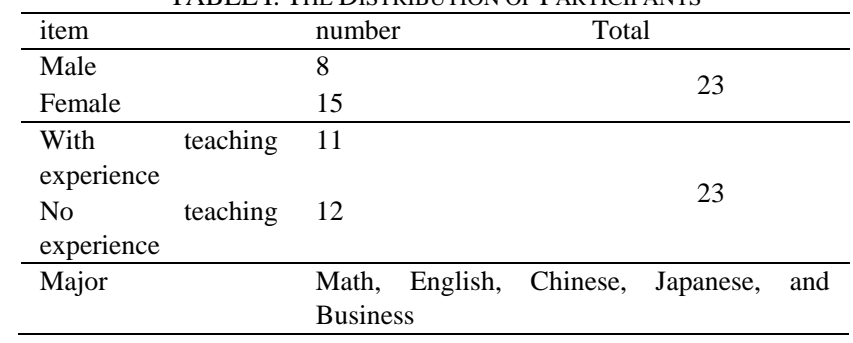

The secondary high school students were low achievement in class. They participated the service learning program because of the secondary high school hope them to increase their learning motivation besides the physical education.

\section{B. Research Procedure}

At this study, the ADDIE instructional model was followed during the curriculum development. Therefore the research procedure was bellows.

First, the analysis stage:

The requirement of the secondary high school was asked. They proposed a demand of increasing the learning motivation of their low achievement students during the summer activities. The pre-service teachers also looked around the school capacities and facilities for their service learning activities in order to have some idea how to develop the summer integrated curriculum.

Second, the design stage:

The pre-service teachers design the service learning activities according to the needs assessment from the analyzing stage. They first come up a core idea and goal for their curriculum, through the international events to expend the low achievement students' views. Since, the pre-service teachers had diversity major, they would develop an integrated curriculum for international events and culture. The Fig. 1 indicated their core idea for integrated curriculum.

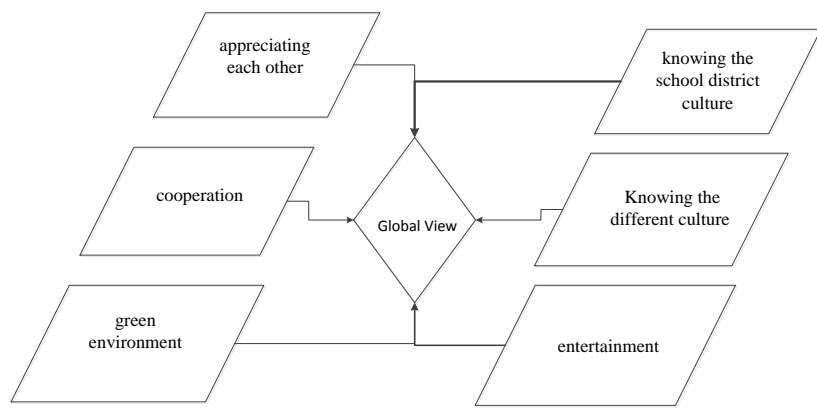

Fig. 1. the integrated core idea.

The Fig. 1 contained the international point of view in the center. Each petal was the nationalization and knowing the school district culture, appreciating each other, cooperation, green environment, entertainment and the different culture.

Third, the develop stage:

According to this integrated curriculum idea, the 
pre-service teachers develop a one weak curriculum for the summer service learning activities. Table II show the detail of

one weak curriculum.

TABLE II: ONE WEAK CURRICULUM

\begin{tabular}{|l|l|l|l|l|}
\hline Date-Time & 8:00-10:00 & $10: 00-12: 00$ & $13: 00-16: 00$ & 16:00-17:00 \\
\hline Mon. & Break Ice & Multi-Culture(I) & Basic manners & Review and work sheet \\
\hline Tues. & Multi-Culture(II) & Multi-Culture(III) & Safeguard of disaster & Review and work sheet \\
\hline Wed. & $\begin{array}{l}\text { Green } \\
\text { protection }\end{array}$ & Green Issue & Law of Green Issue & Review and work sheet \\
\hline Thru. & Famous festival & International flag and country & Multi-culture architecture & Foreign language \\
\hline Fri. & Multi-Culture painting & Multi-culture ballad & Multi-Culture Dialect & Show time \\
\hline
\end{tabular}

In order to develop this integrated curriculum, the pre-service teacher took one month to meet and work together.

Forth, the implementation stage:

Before the pre-service teachers running this summer service learning activities, the two days training was held to help them how to execute the project and the technique they need to learn. The implementation of the service learning activities was held in one weak section total for forty hours. At the end of activities of each day, the evaluating meeting was held. Moreover, each day and each pre-service teacher was asked to write self-reflection.

Fifth, the evaluation stage:

Since at the end of each day the evaluation meeting was held when the implement this summer service learning activities, the pre-service teachers discussed not only the activities themselves but also how the students reaction. Then, as soon as possible, they modified their material and activities for the next day teaching. They developed their teaching experience following the Dewey theory "learning by doing".

At the beginning of this study, when the pre-service teacher signed up to joint this summer service learning activities, they filled out the self- efficacy questionnaire. After one month letter, as soon as they completed the service learning activities, they filled out this questionnaire again.

\section{Research Instrument}

The pre-service teacher self-efficacy questionnaire was modified some others questionnaire. The questionnaire contained 30 questions. There were eleven reverse questions in the questionnaire, item 5, 13, 14, 15, 16, 19, 22, 24, 26, 28, and 29. Pre-service teacher score the number from 1 to 10 for their feeling from very uncomfortable to very comfortable for each question. After the principle components analysis by SPSS, the questionnaire was divided into 4 aspects: class management, teacher qualification, teaching strategies, and the educational theories application. Therefore, the class management contained question $1,2,5,6,9$, and 10. The teacher qualification contained question $4,14,15,16,17$, and 21 . The teaching strategies contained question 12, 13, 20, 22, 23, 27, and 29. At last, the educational theories contained question 18, 19, 24, 25, 26, 28, and 30 .

The each reflection of the pre-service teachers was also analyzed.

The pre-service teacher self-efficacy would be measured with the pre and after test. Moreover, the teaching skill would be measured with their self-reflections. The writing of self-reflection was following these guidelines:

- Content knowledge
- General pedagogical knowledge, with special reference to those broad principles and strategies of classroom management and organization that appear to transcend subject matter

- Curriculum knowledge, with particular grasp of the materials and programs that serve as 'tools of the trade' for teachers

- Pedagogical content knowledge, that special amalgam of content and pedagogy that is uniquely the province of teachers, their special form of professional understanding

- Knowledge of learners and their characteristics

- Knowledge of educational contexts, ranging from workings of the group or classroom, the governance and financing of school districts, to the character of communities and cultures;

- Knowledge of educational ends, purposes, and values, and their philosophical and historical grounds

\section{Data Analysis}

This study used the SPSS 19.0 t test for the research hypothesis.

\section{RESUlTS}

The results of research hypothesis were:

There was no significant difference between the pre-test and post-test in class management.

There was no significant difference between the pre-test and post-test in teacher qualification.

There was significant difference between the pre-test and post-test in teaching strategies.

There was no significant difference between the pre-test and post-test in the educational theories application.

The results show in Table III as below.

\begin{tabular}{lccc}
\multicolumn{4}{c}{ TABLE III: THE RESEARCH RESUlTS } \\
\hline aspects & Pre test & Post test & P value \\
\hline $\begin{array}{l}\text { class } \\
\text { management }\end{array}$ & 20.65 & 20.65 & .785 \\
$\begin{array}{l}\text { teacher } \\
\text { qualification } \\
\text { teaching }\end{array}$ & 39.17 & 38.38 & .546 \\
$\begin{array}{l}\text { strategies } \\
\text { the educational } \\
\text { theories } \\
\text { application }\end{array}$ & 48.48 & 45.83 & $.021^{*}$ \\
\hline
\end{tabular}

The results indicated that the pre-service teachers self-efficacy only the teaching strategies has significant difference between the pre-test and the post-test. However, the average score of the post-test was lower than the average score of the pre-test. Although the other aspects such as class 
management, Teacher qualification, and the educational theories application had no significant different, the average scores of the post-test were also lower than the average score of the pre-test. This study was supposed to provide an opportunity to the pre-service teachers a fields to practice what they had learner in class. Unfortunately, the results did not support the goal for this study.

When looked at the pre-service teacher's self-reflection, it was indicated that they were from exciting and expecting to a little bit sharking.

"Today is the first day of service learning activities. I am very exciting and expecting to meet the students. I am so curious what will be alike about these student..." (day1 PT1)

"Today I am going to teach HAPPY DAY... I am so nervous. So as to I make 2 big mistakes which were taught in class before..."(day3PT1)

"After the closing ceremony, I hear that the student like us and hope we can go to their school for next year summer service learning activities, I am so in touch..."(day5PT1)

"I use the cooperative learning in class. The students are all interested in learning... Although I feel exhausted today, I believe that the students learned what I have taught to them..."(day1PT2)

"Today, the currency exchange course is not so well because the students did not have any motivation on it..."(day2PT2)

"Although team member completes the teaching titled The HAPPY DAY course, the students make many troubles that make many of our team members unhappy..."(day3PT2)

The results indicated that the average score of the post-test was lower than the average score of the pre-test. The same situation was found in the pre-service teachers' self-reflection.

These results may indicate that the pre-service teacher attending the summer service learning activities had a reality shock. Some study (Mahmood, S. 2013) may support that the novices have the reality shock when they first touch in their own field [29]. Some study also point out that the practical teacher have the reality sock in their first teaching year.

The pre-service teacher background factor may cause the results because most of them lack of teaching experience especially the real school setting teaching experience. Therefore, the more data analyzed may need to do in order to find out the relationship between the background factors and the self-efficacy.

\section{CONCLUSION AND SUGgestion}

\section{A. Conclusions}

The purpose of this study is to provide a summer service learning activities for pre-service teacher to practice what they have learned in class. However, there are no significant difference in class management, teacher qualification, and the educational theories application. The teaching strategies aspect has significant difference. Although, the result shows the significant difference, it is not good news for the researcher. Therefore, the researcher interviewed the pre-service teachers tried to find the reasons. At the same time, to understand what they felt about this results and how they would be improved. Fortunately, the pre-service teachers understood the reality shock was due to their highly expecting at the first teaching. Moreover, this experience let them to more careful on choosing courses in order to let them to become good teachers in the future. The results of the study are not support the research hypothesis. However, the summer service learning activities help student enjoy the teaching. In addition, this service learning experience make them to reflect their learning and thinking for the future.

\section{B. Suggestion}

There are some interesting clues in the finding, although the results are not support this study hypothesis. The discussions about the results are mentioned above. Therefore, some suggestions will be provided to the pre-service teachers and to the teacher education curriculum development.

First, some suggestions to the pre-service teachers:

- Taking courses which may enhance the teaching strategies skill

- Attending field teaching as possible as you can

- Second, some suggestions to the teacher education curriculum development:

- Design some field teaching in most courses to let the pre-service teacher understand the real school teaching, such as, visiting the secondary teachers' teaching.

- Providing more real school setting to let the pre-service teacher to practice their teaching, not just only in summer time

- Cooperating with secondary school to develop some field learning course for the pre-service teacher

\section{Future Study}

The results do not support this study hypothesis, the researchers follow up to interview the pre-service teachers trying to find out the reason cause the results. Besides the interview, there are some further studies need to done, such as, to find out if the pre-service teachers' background make difference. What is the import and rare factor that will improve their self-efficacy. Moreover, what kind of the curriculum needs to be modified in order to enhance the pre-service teacher teaching skills. In other words, more research is needed.

\section{REFERENCES}

[1] T. L. Friedman, The World is Flat: A Brief History of the Twenty-First Century, New York, NY: Farrar, Straus and Giroux, 2005, ch. 1.

[2] Every child matters at the heart of the curriculum. (2011). [Online]. Available: http://www.teachfind.com/node/365

[3] No Child Left Behind Act of 2001, "Public Law No.107-110," 2002.

[4] Ministry of Education. (2006). After School Alternative Program. [Online]. Available: http://163.19.64.10/handweb/data/files/200801110545520.doc

[5] Ministry of Education. (2007). Promote Educational Priority Areas Program. [Online]. Available: http://163.25.130.2/advedu/download/96eduplan.doc

[6] J. Dewey, Art as Experience, New York: Capricorn Books, 1934.

[7] J. Dewey, Experience and Nature, New York: Dover Publications, 1958.

[8] J. M. Clerk, A Treatise on Electricity and Magnetism, 3rd ed., vol. 2. Oxford: Clarendon, pp. 68-73, 1892.

[9] K. Lewin, Field Theory in Social Sciences, New York: Harper \& Row, 1951.

[10] I. S Jacobs and C. P. Bean, "Fine particles, thin films and exchange anisotropy," in Magnetism, G. T. Rado and H. Suhl, Ed., New York: Academic, vol. 3, 1963, pp. 271-350. 
[11] J. Piaget, Genetic Epistemology, New York: Columbia University Press, 1970.

[12] Bruner, The Relevance of Education, New York, 1971.

[13] A. Furco, "Service-Learning: A balanced approach to experiential education," Expanding Boundaries: Service and Learning, Washington DC: Corporation for National Service, 1996, pp. 2-6.

[14] J. S Eyler, "What do we most need to know about the impact of service-learning on student learning?" Michigan Journal of Community Service Learning, pp. 11-17, 2000.

[15] S. Karayan and P. Gathercoal, "Assessing Service-Learning in Teacher Education," Teacher Education Quarterly, pp. 79-92, 2005.

[16] P. Dillenbourg. Collaborative Learning Cognitive and Computational Approaches, New York, 1999, ch. 1.

[17] L. M. Nelson, "Collaborative problem solving," in Instructional-Design Theories and Models A New Paradigm of Instructional Theory, C. M. Reigeluth, Ed., New Jersey Lawrence Erlbaum Associates publishers, ch. 11, pp.241-268.

[18] F. B. Murray, "Why understanding the theoretical basis of cooperative learning enhances teaching success," Creativity and Collaborative Learning A Practical Guide to Empowering Students and Teachers, ch. 1, pp. 3-11.

[19] C. L. Hsu and Y. F. Chang, "Study of the relationship with the media material and the students' learning motivation," J. Educational Study, vol. 116, pp. 64-76, 2003.

[20] C. L Hsu, "E-CAI case study," Educational Technology and Media, vol. 33, pp. 28-35, 1997.

[21] C. L Hsu and C. H Kuo, "Study of e-learning material technology," in Proc. 2000 e-Learning Theory and Practice Conference, National Chiao Tung University, Shin-Chu, 2000, pp. 61-65.

[22] C. C Hsu, L. H Wang, C. F. Hong, M. Y Sung, and P. H Tasi, "The KeyGraph perspective in ARCS motivation model," in Proc. the 6th
IEEE International Conference on Advanced Learning Technologies, 2006, New York: IEEE Press, pp. 970-974.

[23] C. C Hsu, L. H. Wang, and C. F. Hong, "Understanding students' conceptions and providing scaffold teaching activities," in Proc. International Conference of Teaching and Learning for Excellence, Tamsui, 2007, pp. 166-175.

[24] C. J. Marsh and G Willis, Curriculum Alternative Approaches, Ongoing Issues, New Jersey: Prentice-Hall Inc, 1999.

[25] P. L. Smith and T. J. Ragan, Instructional Design, New York: Macmillan, 1993.

[26] R. M. Gagne, L. J. Briggs, and W. W. Wager, Principles of Instructional Design. Fort Worth, TX: Harcourt Brace Jovanovich, 1992.

[27] T. Michael, M. Marlon, and J. Roberto, "The third dimension of ADDIE: A cultural embrace," TechTrends, vol. 46, no. 12, pp. 40-45, 2002.

[28] C. L. Hsu and C. H. Kuo, "The study of web material," in Proc. 2000 Conference on Web Learning Theory and Practice, Taiwan, 2000, pp. 61-65.

[29] S. Mahmood, "Reality shock: New early childhood education teachers," Journal of Early Childhood Teacher Education, vol. 34, no. 2, pp. 154-170, May 3, 2014.

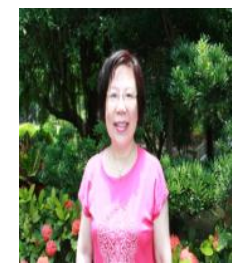

Chia-ling Hsu was born in Taipei, on Oct. 18, 1957. She graduated at University of Missouri, Columbia She received her $\mathrm{PhD}$ in curriculum and instruction, Education School. She worked in Tamkang University, No.151, Yingzhuan Rd Tamsui Dist., New Taipei City 25137 Taiwan (R.O.C.) Center for teacher education associated professor. 